\title{
An Unusual Case of Relay Pentobarbital Toxicosis in a Dog
}

\author{
Karyn Bischoff • Robin Jaeger • Joseph G. Ebel
}

Published online: 10 June 2011

(C) American College of Medical Toxicology 2011

\begin{abstract}
Sodium pentobarbital and phenytoin are common constituents of veterinary euthanasia solutions in the United States. Relay, or secondary, barbiturate toxicosis has been reported in carnivorous animals that have fed from the carcasses of euthanized livestock. This case report presents barbiturate toxicosis in a dog. A 2-year-old female spayed Australian shepherd presented comatose $2 \mathrm{~h}$ after ingesting an unknown substance on the beach. The material was retrieved from the stomach by gastric lavage and visually identified as fish or other animal tissue. The dog recovered with symptomatic and supportive therapy and was released on the third day of hospitalization. Tissue found on the beach near where the dog walked and a urine sample from the dog were analyzed by gas chromatography/mass spectrometry. Both samples were positive for pentobarbital and phenytoin. The tissue was consistent with mammalian
\end{abstract}

This study has been presented at the American Association of Veterinary Comparative Toxicologists in Minneapolis, MN, November 2010, and in South Korea at the National Veterinary Research and Quarantine Services, Anyang, the College of Veterinary Medicine at the Seoul National University, and at the College of Veterinary Medicine at Cheju National University in October 2010.

\section{K. Bischoff $(\bowtie)$}

Department of Population Medicine and Diagnostic Sciences, Cornell University and New York State Animal Health Diagnostic Center,

PO Box 5786, Ithaca, NY 14853, USA

e-mail: KLB72@cornell.edu

R. Jaeger

East End Veterinary Emergency,

67 Commerce Drive,

Riverhead, NY 11901, USA

J. G. Ebel

New York State Animal Health Diagnostic Center,

PO Box 5786, Ithaca, NY 14853, USA blubber based on gross and histological examination. Three weeks previously, a juvenile humpback whale had stranded on the beach where the dog had ingested the unknown substance. The whale had been euthanized with a barbiturate solution, necropsied, and removed from the beach. It was not definitively determined that the pentobarbitalcontaining blubber ingested by the dog was from the euthanized whale, but that was the most likely source. Although attempts were made to remove the whale's remains from the beach, practical considerations made complete removal challenging, if not impossible.

Keywords Barbiturates · Dog $\cdot$ Pentobarbital $\cdot$ Relay toxicosis $\cdot$ Secondary poisoning

\section{Introduction}

This case report documents an unusual case of relay toxicosis in a dog due to ingestion of mammalian tissues containing pentobarbital. Although the use of barbiturates by physicians is relatively uncommon, pentobarbital, a short-acting barbiturate, is still routinely used in veterinary medicine for anesthesia, seizure control, and as the primary drug used for euthanasia [1, 2]. Domestic animals, wildlife, and zoo animals have been accidentally exposed to pentobarbital and other barbiturates through ingestion of tissue from euthanized animals [2-6].

The primary mechanism of action of barbiturates is through binding to the $\gamma$-amino butyric acid complex (GABA) and decreasing the rate of GABA dissociation, thus enhancing its inhibitory effects. The expected clinical signs range from ataxia and poor coordination to marked obtundation, anesthesia, and suppression of respiration and reflexes $[2,4,5]$. 


\section{Case Study}

A 25-month-old female spayed Australian shepherd weighing $20.2 \mathrm{~kg}$ was brought to a veterinary clinic acutely unresponsive. Two hours previously, this dog was taken to the beach for exercise, where it discovered and ingested a fragment of meat- or fish-like material. The patient had no known exposure to drugs or other toxicants known to cause sedation in dogs, such as ivermectin, benzodiazepines, opiates, cannabis, or macadamia nuts, and had no relevant previous medical history to explain the current coma. There were no reports of red tide on the beach, and no ticks or wounds were found on the dog at the time of presentation.

On presentation to the local veterinarian, the dog was nonresponsive to stimulation with no withdrawal or deep pain response. Her gag reflex was absent. She had mildly miotic pupils with an intact papillary light reflex and protruded nicitating membranes. Her initial systolic blood pressure was within the expected range for a medium-sized dog (128 $\mathrm{mmHg}$, average ranges from $118 \mathrm{mmHg}$ for small breeds to $136 \mathrm{mmHg}$ for large breeds [7]). Abdominal radiographs revealed the presence of granular radio-opaque material in the stomach. With the recent history of ingesting material on the beach, the radio-opaque material was interpreted as sand. During initial treatment, the dog received $1 \mathrm{~L}$ of lactated Ringer's solution (LRS) via intravenous (IV) catheter over 2 h. She was intubated and underwent gastric lavage; however, minimal material was recovered from the stomach. Activated charcoal was administered via the gastric tube after the lavage was complete.

The patient was transferred to a veterinary emergency care clinic. Upon examination at the emergency clinic she was comatose: unresponsive to sound, negative menace, absent gag reflex, closed eyes, protruded nictitating membranes, and dribbling urine. Her palpebral and pupillary light reflexes were intact. There were no abnormalities noted on thoracic auscultation. The spleen was enlarged on abdominal palpation. Sand and loose feces were noted on digital rectal palpation. Other clinical findings included a rectal temperature of $36.2^{\circ} \mathrm{C}\left(97.2^{\circ} \mathrm{F}\right.$, expected value of $38.9^{\circ} \mathrm{C}$ or $\left.102^{\circ} \mathrm{F}\right)$, heart rate of 130 beats/min ( $70-120$ beats/min), 30 breaths/ $\min (18-34$ breaths $/ \mathrm{min})$, capillary refill time $<2 \mathrm{~s}$, and $\mathrm{PO}_{2}=$ $93 \mathrm{mmHg}(>95 \mathrm{mmHg})$. A serum chemistry profile and complete blood count were performed upon admission. Chemistry abnormalities included the following: phosphorus $10 \mathrm{mg} / \mathrm{dl}$ (reference values 2.9-6.6 mg/dl; VetScan, Abaxis, Union City, CA), glucose $114 \mathrm{mmol} / \mathrm{l}(60-110 \mathrm{mmol} / \mathrm{dl}$; VetScan), globulin $1.2 \mathrm{~g} / \mathrm{dl}(2.3-5.2 \mathrm{~g} / \mathrm{dl}$; VetScan), hematocrit 36.7\% (37-55\%; Idexx, Lasarcyte, Westbrook, ME), total serum protein $4.4 \mathrm{~g} / \mathrm{dl}(5.4-8.2 \mathrm{~g} / \mathrm{dl}$; VetScan), and mean corpuscular volume $79.6 \mathrm{fl}(60-77 \mathrm{fl}$; Idexx). The reported hyperphosphatemia was likely spurious; reduced GFR, dietary, or metabolic causes secondary to disturbances in bone and calcium metabolism were considered unlikely [8]. Mild hyperglycemia was suspected to be due to systemic stress, but could also have been due to recent food ingestion. The hypoglobulinemia and low total protein could have been spurious or due to fluid dilution; a protein losing enteropathy was considered unlikely as the dog had no reported gastrointestinal symptoms previously. The mild anemia could also have been due to fluid dilution, as the patient had received a liter of LRS at the referring veterinarian prior to transfer.

Due to a recent whale stranding, it was considered a possibility that while on the beach, the dog was exposed to either contaminated whale meat or a reportedly lost dart. It was initially reported that sedatives contained in the dart could include detomidine, meperidine, midazolam, xylazine, and butorphanol.

Initial treatment included intubation, oxygen supplementation, supplemental heat, and IV fluid administration. Warm soapy enemas were performed twice over $6 \mathrm{~h}$ and produced large amounts of fecal material containing activated charcoal. A second gastric lavage retrieved sand and fish- or meat-like tissue. The dog remained comatose overnight.

The following day, the dog remained recumbent and intubated; however, she opened her eyes when stimulated. Repeat abdominal radiographs indicated a diminished amount of sand in the stomach and progression of sand into the small intestine. Additionally, the distal thoracic esophagus was dilated. Serum phosphorus had returned to normal $(5.7 \mathrm{mg} / \mathrm{dl})$. Atipamezole was administeredin case of exposure to an alpha-2 adrenergic agonist. Mild improvement was noted: the dog weakly picked up her head and chewed on the endotracheal tube. Intravenous lipids (Intralipid 20\%; Fresenius Kabi for Baxter Healthcare, Clintec Nutrition Division, Deerfield, IL) were administered, in case a lipid soluble toxin was present, at a $1.5 \mathrm{ml} / \mathrm{kg}$ bolus dose, then $0.25 \mathrm{ml} \mathrm{kg}^{-1} \mathrm{~min}^{-1} \mathrm{CRI}$ over an hour. The lipid bolus and infusion was repeated $4 \mathrm{~h}$ later. During the second lipid infusion, the dog became more alert and started to pick her head up. The dog also received metoclopramide at $2 \mathrm{mg} \mathrm{kg}^{-1}$ day $^{-1}$ IV CRI to facilitate gastric emptying. Twenty-four hours after presentation to the emergency hospital, the dog slowly and progressively became more alert and hypersensitive to noise. By $36 \mathrm{~h}$ she was awake and responsive, began eating, and was ambulatory. She was discharged to the care of her owner $60 \mathrm{~h}$ after presentation and was considered fully recovered.

A urine sample taken from the patient during hospitalization tested positive for barbiturates using a human overthe-counter drug testing kit (First Check; Iverness Medical, Waltham, MA). A subsample of the urine was sent to the kit manufacturer for confirmation, but the presence of barbiturates was not confirmed via gas chromatography/mass spectrometry (GC/MS). Material from the gastric lavage was no longer available for testing, but a sample of the 
material the dog had been eating was retrieved from the beach and brought in with the dog at presentation (Fig. 1). This material and a subsample of the original urine sample were later analyzed by the Analytical Toxicology Laboratory at the New York State Animal Health Diagnostic Center (AHDC) via capillary GC/MS. The submitted material from the beach measured approximately $8 \times 6 \times 4 \mathrm{~cm}$ and had an approximately $0.4-\mathrm{cm}$-thick black band consistent with epidermis along one surface. Beneath the epidermis was a thick band of firm adipose and connective tissue, consistent with hypodermis, through which coursed bundles of muscle. Pentobarbital was detected in the urine and tissue from the beach at concentrations of $4.0 \mu \mathrm{g} / \mathrm{ml}$ and $321.5 \mu \mathrm{g} / \mathrm{g}$ wet weight, respectively. Both samples contained phenytoin. Additionally, the urine contained metoclopramide. Concentrations of these drugs were not determined.

A subsample of the unknown material was placed in formalin and submitted to histopathology for further characterization. Erythrocytes in the sample were anucleate and biconcave, confirming that the tissue was of mammalian origin. Histologic findings were consistent with marine mammal epidermis and blubber.

Twenty-three days before the dog was presented to the hospital, a juvenile humpback whale had stranded on the beach in approximately the location the dog had accessed. Surf and beach conditions precluded a safe rescue attempt; therefore, humane euthanasia was considered appropriate. Intravenous drug administration initially was not possible due to the whale's position and safety concerns for the involved people. Early sedation attempts used 12-in darts that could penetrate through blubber and contained detomidine, midazolam, and butorphanol. After multiple attempts, the whale was sedated. Approximately $12 \mathrm{~h}$ later,

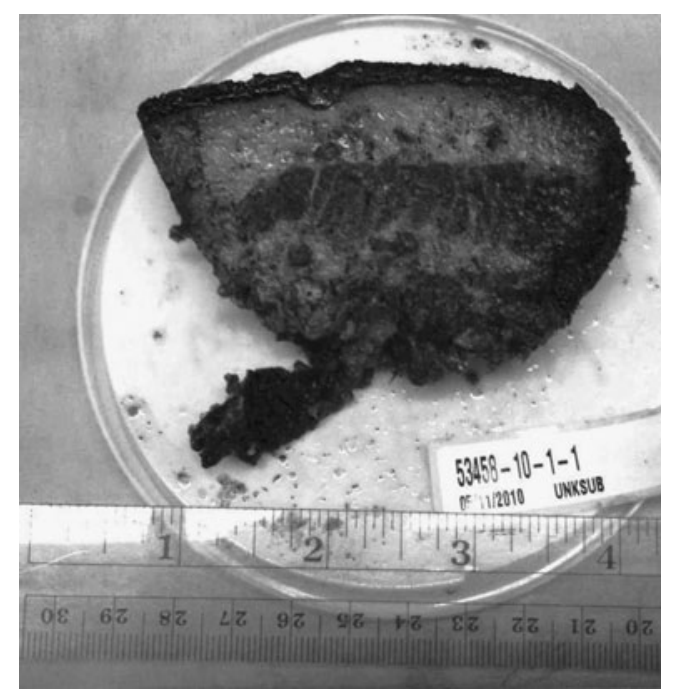

Fig. 1 Tissue submitted to the laboratory for analysis. This material was found on the beach in the area the dog was walked and closely resembled material recovered via gastric lavage three pericranial 0.577 ballistic rounds were administered, and then the whale was euthanized with barbiturate euthanasia solution via IV and intraperitoneal injection. Stringent efforts were made to ensure all remains were removed from the beach after a post-mortem examination.

\section{Discussion}

Paralytic diseases were considered as a possible cause of clinical signs in this dog, including tick paralysis, saxitoxin poisoning from red tide, botulism from carrion ingestion, or macadamia nut ingestion (macadamia nuts cause marked muscle weakness in dogs), but in these toxicoses, the patient is likely to remain alert. Causes of marked sedation and coma are more likely to include ingestion of pharmaceuticals or illicit drugs such as barbiturates, benzodiazepines, opioids, cannabis, or ivermectin (a veterinary drug). Clinical signs of barbiturate toxicosis can be apparent 30 min after ingestion, but onset is delayed with the presence of food in the stomach $[1,2]$. Barbiturates enhance stimulation of GABA receptors in the sensory and motor cortex, and possibly the thalamus, producing sedative-hypnotic effects [1]. The resulting presentation is attributable to central nervous system depression and anesthesia $[2,4,5]$. Tachycardia, hypothermia, and splenomegaly are also typically reported $[2,5]$. Because death from barbiturate overdose is usually caused by respiratory suppression, respiratory support is often required $[2,4,5]$. This dog's clinical signs and slow recovery were typical of barbiturate overdose.

This dog recovered over a 3-day period with symptomatic and supportive care. Early decontamination was attempted because of the ingestion of unknown material 2 $\mathrm{h}$ before presentation. Activated charcoal was administered to promote fecal excretion of barbiturates [2, 5]. Gastric lavage of the intubated patient facilitated removal of the ingested material [5]. Unfortunately, material from the gastric lavage was not saved for future testing. Supportive care measures such as IV fluid infusion and heat blankets helped to maintain hydration and stabilize electrolyte balance and maintain body temperature.

This dog was given atipamezole because exposure to an alpha-2 adrenergic agonist was suspected, either through ingestion of meat from the whale or from exposure to the lost dart. The dog showed evidence of mild response to atipamezole treatment, but this was most likely incidental because no alpha-2 adrenergic agonists were detected by $\mathrm{GC} /$ MS in the dog's urine or the tissue sample from the beach. Kinetics of the drugs possibly contained in the dart including detomidine, meperidine, midazolam, xylazine, and butorphanol have not been evaluated in cetaceans, but all are rapidly metabolized and eliminated in other species; it was approximately $12 \mathrm{~h}$ between sedation and time of death [9-12]. 
Due to radiographic evidence of gastric stasis, metoclopramide was administered to promote gastric motility and was later detected in the urine by GC/MS analysis at AHDC. Intravenous lipid emulsion is used to treat patients overdosed with local anesthetics or other lipid soluble drugs and is theorized to reduce drug bioavailability by providing a lipid sink $[13,14]$. There was a moderate response of increased alertness noted during the second lipid infusion that could have been attributed to the lipid administration.

The stranded whale was euthanized using barbiturates and removed from the beach approximately 3 weeks before the dog presented for sedation caused by pentobarbital and phenytoin after ingestion of contaminated mammalian blubber. It cannot be definitively confirmed that the blubber came from this whale without genetic testing, nor can it be confirmed that the sample tested was the same as the material originally retrieved from the dog's stomach, though it was similar based on appearance and location. Genetic testing on a subsample of the same specimen obtained from the beach was performed by a government agency, but the results are unavailable to the authors at this time. Further genetic testing was not pursued due to financial constraints. A common euthanasia solution used in veterinary medicine contains $390 \mathrm{mg}$ pentobarbital sodium and $50 \mathrm{mg}$ phenytoin sodium per milliliter. Both of these drugs were detected in the sample retrieved from the beach and in the dog's urine via GC/MS at AHDC. Therefore, the euthanized whale was the most likely source of the blubber that produced clinical signs consistent with barbiturate overdose in the dog. It is not known why the first laboratory did not detect pentobarbital and phenytoin in the urine sample, though that laboratory is strictly for human urine samples (not canine) and the GC/MS technique used had a higher detection limit than the AHDC technique.

Accidental barbiturate poisoning after ingestion of euthanized livestock has been reported in domestic dogs and wildlife, and euthanized animals are occasionally used to feed carnivores, sometimes in zoo settings [2-6]. Other cases have been reported in carnivorous wildlife that ingested euthanized domestic animals. One report attributed the deaths of 34 eagles to foraging on carcasses of domestic animals that had been euthanized with barbiturate euthanasia solution, and five bald eagles and two golden eagles died from barbiturate poisoning after scavenging the carcasses of euthanized mules in Colorado in 1999 [6].

The circumstances of this case were unique. A wild animal was euthanized and the size of the animal, a juvenile humpback whale 7-9 $\mathrm{m}$ long, weighing approximately $13 \mathrm{t}$ (approximately 11,800 kg), made carcass removal challenging at best. The whale remains were not intact at the time of removal due to the post-mortem examination done at the beach. When performing the necropsy of such a large animal on the beach, loose tissues could easily become lost in the sand or surf, only to reappear later. Therefore, failure to remove all whale tissue from the beach is not surprising, and likely impossible under the circumstances. In this case, the dog exposed to the contaminated tissue exhibited classic clinical signs of barbiturate toxicosis. Fortunately, the owners quickly sought out veterinary assistance and after 3 days of hospitalization she was discharged fully recovered.

Acknowledgements We thank the Anatomic Pathology Service at the Cornell University College of Veterinary Medicine. Special thanks to Jonathan Turetetsky, DVM, of East Hampton Vet Clinic, and Rachel Goldfarb, DVM, of East End Veterinary Emergency Center.

Conflict of Interest Funding for this case study was private and the authors have no conflicts of interest

\section{References}

1. Branson L (2001) Injectable anesthesia. In: Adams R (ed) Veterinary pharmacology and therapeutics, 8th edn. Iowa State University Press, Ames, pp 213-267

2. Kisseberth WC, Trammel HL (1990) Illicit and abused drugs. Vet Clin N Am Small Anim Pract 20(2):405-418

3. Hewitt S, Williamson S, Woodger N, Streete P, Cracknell J, Lewis $\mathrm{J}$ (2010) Secobarbital poisoning in an Amur tiger (Panthera tigris altaica). Vet Rec 167(5):178-180

4. Humphreys DJ, Longstaffe JA, Stodulski JB, Fysh RR, Lopatkin I (1980) Barbiturate poisoning from pet shop meat: possible association with perivascular injection. Vet Rec 107(22):517

5. Volmer P (2005) Recreation drugs. In: Peterson ME, Talcott PA (eds) Small animal toxicology, 2nd edn. Saunders, Philadelphia, PA, pp 273-311

6. O'Rourk K (2002) Euthanized animals can poison wildlife: veterinarians receive fines. J Am Vet Med Assoc 238(2):130-145

7. Anonymous. Breed specific reference data. In: S\&B MedVet, http://www.submedvet.com/Php/frmbuilder.php5?dateiname $=\%$ 2FDocs\%2FMemo_diagnostic\%2Freference_values.html. Accessed March 24, 2011

8. Duncan JR, Prasse KW, Mahaffey EA (1994) Veterinary laboratory medicine clinical pathology, 3rd edn. Iowa State University Press, Ames, pp 193-194, 235-238

9. Hubbell JAE, Sams RA, Schmall LM, Robertson JT, Hinchcliff KW, Muir WW (2009) Pharmacokinetics of detomidine administered to horses at rest and after maximal exercise. Equine Vet J 41(5):419-422

10. Plumb D (2002) Veterinary drug handbook, 4th edn. PharmaVet Publishing, White Bear Lake, pp 555-556

11. Qiao GL, Fung KF (1993) Pharmacokinetic-pharmacodynamic modeling of meperidine in goats: I. Pharmacokinetics J Vet PharmacolTherap 16(4):426-437

12. Sellon DC, Papich MG, Palmer L, Remund B (2008) Pharmacokinetics of butorphanol in horses after intramuscular injection. J Vet Pharmacol Ther 32(1):62-65

13. Corman SL, Skledar SJ (2007) Use of lipid emulsion to reverse local anesthetic-induced toxicity. Ann Pharmacother 41(1):1873-1877

14. Crandell DE, Weinberg GL (2009) Moxidectin toxicosis in a puppy successfully treated with intravenous lipids. J Vet Emerg Crit Care 19(2):81-186 